\title{
NOVOS ARRANJOS FAMILIARES, VELHAS CONVENÇÕES SOCIAIS DE GÊNERO: A LICENÇA-PARENTAL COMO POLÍTICA PÚBLICA PARA LIDAR COM ESSAS TENSÕES
}

\author{
LUANA PINHEIRO \\ Secretaria Especial de Políticas para as Mulheres \\ MARCELO GALIZA \\ Instituto de Pesquisa Econômica Aplicada \\ NATÁLIA FONTOURA \\ Instituto de Pesquisa Econômica Aplicada
}

\begin{abstract}
Resumo: O objetivo deste artigo é tratar o descompasso entre as transformações percebidas nas estruturas familiares e a forma como o Estado responde a essas questões por meio de políticas públicas fundamentadas em um modelo estrito e convencional de família (nuclear, formada por casal com filhos) que reafirma convenções tradicionais de gênero. Como exemplo ilustrativo desse descompasso, trabalhamos o caso das licenças para cuidado de filhos/as utilizando, para isto, as informações produzidas pela pesquisa Retrato das Desigualdades, que evidenciam o surgimento de novos modelos de arranjos familiares.
\end{abstract}

Palavas-chave: gênero; mulheres; políticas públicas; licença-parental; licença-maternidade.

\section{Introdução}

A sociedade brasileira vem passando por importantes e profundas alterações em sua estrutura. Há algumas décadas vimos assistindo a uma permanente queda da

Copyright $\odot 2009$ by Revista Estudos Feministas. 
hegemonia do modelo de família formada por casal com filhos, ao passo que, no mercado de trabalho, vem aumentando cada vez mais a participação das mulheres. Os brasileiros vivem mais e têm menos filhos, e a sociedade é cada vez mais urbana.

Se essas transformações refletem diferentes possibilidades de construção dos arranjos sociais, é forçoso reconhecer que a consolidação de novos padrões de comportamento e valores demanda, por um lado, um investimento contínuo e intenso dos movimentos sociais e, por outro, uma atuação contundente e não conservadora do Estado na construção de outro referencial de políticas públicas que, ao mesmo tempo, estimule e reconheça as mudanças em curso na sociedade.

O objetivo do presente artigo é tratar o descompasso entre as transformações percebidas nas estruturas familiares e a forma como o Estado responde a essas questões por meio de políticas públicas fundamentadas em um modelo estrito e convencional de família (nuclear, formada por casal heterossexual com filhos) que reafirma convenções tradicionais de gênero. ' Como exemplo ilustrativo desse descompasso, trabalhamos o caso das licenças para cuidado de filhos/as utilizando, para isto, as informações produzidas pela pesquisa Retrato das Desigualdades, que evidenciam o surgimento de novos modelos de arranjos familiares.

\section{Transformações recentes nas famílias e descompasso da ação do Estado}

A despeito das transformações verificadas nas famílias brasileiras nos últimos anos, o arranjo mais comumente encontrado, ainda, é aquele do tipo 'casais com filhos', arranjo normalmente relacionado ao conceito de 'família' presente no imaginário coletivo, isto é, a família nuclear, heterossexual. Em 2007, essa estrutura familiar respondia por $52 \%$ das famílias brasileiras.

A preponderância das famílias formadas por casais com filhos, no entanto, vem decaindo (em 1993, equivalia a 63\%), ao passo que vem aumentando a importância de outros tipos de famílias, como casais sem filhos, mulheres e homens morando sozinhos e famílias monoparentais masculinas ou femininas. Este último tipo, o segundo mais encontrado no país, respondia por quase 13\% das famílias em 1993 e, em 2007, chegou a $15,4 \%$ dos arranjos familiares. ${ }^{2}$

Importante sublinhar a percepção de que estaria ocorrendo também um aumento do número de famílias homoafetivas, ainda que não se tenham informações oficiais sobre esse fenômeno. Outra tendência pesquisada mais recentemente foi o aumento do número de casais sem filhos, mais presente nas classes média e alta e também diretamente ligado a transformações culturais significativas, que questionam a 'obrigação' social de constituição de famílias com filhos. ${ }^{3}$

A crescente inserção das mulheres no mercado de trabalho é outro importante aspecto a ser considerado no estudo sobre as famílias brasileiras. É verdade que esse fenômeno não se deve somente a questões culturais e que, também, não se apresentou da mesma forma para todas as mulheres. Para as mulheres de classes mais baixas, por exemplo, a entrada no mercado de trabalho - como resposta a uma necessidade de complementar a

\footnotetext{
${ }^{1}$ Convenções estas que colocam o homem e a masculinidade como interligados à função do trabalho e do provimento de renda e a mulher e a feminilidade, como naturalmente constituídas pelas tarefas de cuidado e de reprodução social.

2 Luana PINHEIRO et al., 2008.

${ }^{3}$ José Eustáquio ALVES e Suzana CAVENAGHI, 2007.
} 
renda familiar - já era uma realidade há muito mais tempo. De todo modo, as taxas de participação feminina aumentaram substancialmente nas últimas décadas e estão associadas, entre outros fatores, às transformações culturais, à redução da fecundidade, ao gradual aumento no nível de escolaridade e à necessidade de aumentar a renda das famílias, especialmente durante a década de 1990, marcada pela estagnação econômica e pela precarização das ocupações de forma geral.

Tal inserção, aliada à maior participação feminina no rendimento total das famílias nas quais há um companheiro, pode interferir na organização familiar, alterar as relações de gênero em seu interior e afetar a distribuição interna de poder e a divisão do trabalho entre os diferentes membros do grupo familiar, levando a um possível maior empoderamento das mulheres. É importante frisar, entretanto, que, apesar de explicitar transformações comportamentais importantes, os avanços são lentos e estão longe de representar uma divisão sexual do trabalho doméstico mais equitativa.

Ao se analisar a atualidade das relações de gênero no contexto nacional, fica evidente, também, o descompasso entre mudanças sociais e reconhecimento institucional. Ao lado das novas formas de organização da sociedade convivem arcaicas estruturas, como normas, leis, políticas e sentenças judiciais, que não condizem com a prática efetiva da vida cotidiana. Muitos comportamentos baseados nas convenções sociais de gênero também não se coadunam com as novas formas de organização da sociedade. Daí a importância de o Estado, por um lado, intervir para transformar esses comportamentos, reprodutores da desigualdade, e, por outro, incentivar aquelas transformações que vêm ocorrendo na sociedade.

Portanto, dessa crescente tensão entre a dinâmica da vida social e as convenções de gênero uma série de demandas sociais emerge. O aparato legal e as políticas públicas, de forma geral, foram arquitetados para um modelo de família heterossexual tradicional no qual o lugar simbólico do homem como provedor e da mulher como cuidadora do lar impera. Fora desse modelo - cada vez menos representativo das famílias brasileiras - os níveis de desproteção legal e social podem ser significativos.

Não se pode negar que, em alguma medida, a regulação (estatal ou não) das práticas sociais tem acompanhado o processo de mudança cultural em curso. Políticas relativas à inserção das mulheres no mercado de trabalho e ao reconhecimento da união civil entre casais homoafetivos, entre várias outras afins, são objetos constantes de debates, conformam a agenda política e, frequentemente, resultam em novas legislações e políticas públicas.

Nesse sentido, assumindo que a equidade é o objetivo fundamental em si mesmo para qualquer sociedade que se pretenda democrática, este texto defende que o papel do Estado nesse processo deve ser mais propositivo, objetivando não apenas assegurar proteção social e legal às famílias, em suas mais variadas composições, mas também estimular o processo de transformação das convenções sociais de gênero na direção de uma sociedade mais igualitária. A partir de uma análise das normas que regulam o mercado de trabalho, argumentamos que a atuação do Estado brasileiro, ao contrário, está distante desses objetivos: os direitos trabalhistas relacionados à proteção à família, além de terem cobertura bastante limitada, reforçam a concepção tradicional de família composta de um 'homem provedor' e uma 'mulher dedicada aos cuidados do lar', com sérios rebatimentos sobre a inserção feminina no mercado de trabalho e sobre a divisão sexual do trabalho reprodutivo.

A legislação trabalhista brasileira prevê um conjunto de medidas no que diz respeito à proteção à família. Entre os principais direitos garantidos às mães estão a estabilidade para a gestante (desde a confirmação da gravidez até cinco meses após o parto), a 
licença-maternidade (de 120 dias, extensível por mais 60 dias), o salário-família (auxílio financeiro por filho de até 14 anos de idade ou inválidos de qualquer idade, inversamente proporcional ao valor do salário mensal), o intervalo para amamentação (até que o bebê complete seis meses de idade) e a existência de creche custeada pela empresa ou o pagamento de auxílio-creche (nos primeiros seis meses de vida dos filhos). Entre os direitos garantidos aos pais estão a licença-paternidade (de cinco dias após o nascimento do filho) e o salário-família (benefício que pode ser recebido, simultaneamente, por mães e pais). É nítido, portanto, que os benefícios previstos focalizam, prioritariamente, os direitos reprodutivos das mulheres, oferecendo poucas possibilidades aos homens de se comprometerem com o exercício da paternidade responsável, bem como ignorando a existência de famílias homoafetivas e monoparentais masculinas. Nesse contexto, nota-se que o aparato legal contribui no mínimo para a manutenção e a reprodução de uma realidade bastante desigual no que diz respeito à divisão sexual do trabalho reprodutivo.

Todos os direitos previstos, vale destacar, são assegurados apenas para os trabalhadores formais, que representam menos da metade da força de trabalho ativa do país. Quando o olhar se direciona às mulheres ocupadas, potenciais beneficiárias da maior parte dos direitos atualmente previstos, nota-se que apenas $38,1 \%$ dessas mulheres estavam ocupadas no mercado de trabalho formal em $2007,{ }^{4}$ ou seja, além de explicitar um claro viés de gênero, a legislação trabalhista oferece uma cobertura bastante restrita aos trabalhadores e suas famílias.

É importante ressaltar que, além de reforçar as tradicionais convenções sociais de gênero, o viés incutido na concepção dos benefícios trabalhistas também pode explicar, em alguma medida, o abismo que separa as remunerações do trabalho masculino e feminino - manifestação mais evidente da discriminação que as mulheres sofrem no mercado de trabalho. Argumenta-se recorrentemente que os menores salários das mulheres em comparação aos dos homens se justificariam pela necessidade de as empresas compensarem os mais altos custos associados ao trabalho feminino, uma vez que dispositivos legais de proteção à maternidade e ao cuidado infantil incidem sobre a contratação de mulheres, e não sobre a contratação de homens.

Essa questão, na verdade, é controversa, tendo sido concluído por Laís Abramo e Rosalba Todaro, por exemplo, que "os custos adicionais para o empregador relacionados à contratação das mulheres são muito reduzidos e não explicam as desigualdades entre homens e mulheres". ${ }^{5}$ Argumenta-se aqui, entretanto, que, independentemente de os custos monetários envolvidos na contratação de mulheres serem mais altos ou não, os benefícios concedidos pela legislação trabalhista, ao focalizarem prioritariamente os direitos reprodutivos das mulheres, consideram que o papel delas na reprodução social é um dado inquestionável e o dos homens, por sua vez, marginal.

Nesse sentido, a regulação social do trabalho naturaliza a ideia da maternidade como destino feminino, reforçando a permanência de dois pressupostos predominantes na organização do trabalho brasileiro: o da existência de uma divisão sexual do trabalho não mercantil, que implica a existência de uma mulher responsável pelas pesadas tarefas do cuidado doméstico; e o do paradigma do 'trabalhador normal', que supõe um indivíduo do sexo masculino que não tem vida pessoal e que, portanto, deve ter disponibilidade total para o trabalho produtivo e nenhuma possibilidade ou necessidade de realizar qualquer tipo de trabalho, esforço ou dedicação no universo familiar. ${ }^{\circ}$

\footnotetext{
${ }^{4}$ PINHEIRO et al., 2008.

${ }^{5}$ Laís ABRAMO e Rosalba TODARO, 2008, p. 148.

${ }^{6}$ ABRAMO e TODARO, 2008.
} 
Portanto, ainda que se argumente que o custo monetário do trabalho feminino não seja muito mais alto do que o do masculino, já que, no Brasil, tais custos representam apenas $1,2 \%$ da remuneração bruta mensal das mulheres, segundo calculam Laís Abramo e Rosalba Todaro, as regras que atualmente regulam o trabalho reforçam a ideia (e a própria prática, como já foi mencionado) de que cabe às mulheres o papel de cuidadoras do lar, o que faz com que o custo do trabalho produtivo feminino, em termos relativos, seja sempre considerado mais alto devido ao impacto negativo das atividades femininas extraprofissionais na produtividade das empresas. Tal impacto se expressaria, por um lado, por sua menor disponibilidade para realizar atividades fora dos horários normais de trabalho e, por outro, pela maior ocorrência de ausências não programadas para o cuidado dos filhos e de outros membros da família.

Os significativos diferenciais de salário entre homens e mulheres não são, contudo, as únicas manifestações da discriminação que elas sofrem no mercado de trabalho. A naturalização do papel das mulheres como responsáveis pela reprodução da família reforçada pela legislação trabalhista vigente - se reflete, por exemplo, nas menores oportunidades de acesso das mulheres aos cargos de maior responsabilidade e hierarquicamente superiores, uma vez que elas, supostamente, teriam menos disponibilidade e até interesse em se dedicar ao trabalho dito produtivo. Nesse contexto, argumenta-se, aqui, que a implementação de qualquer política com o intuito de reduzir as diferenças nas médias salariais, nas condições de trabalho e nas oportunidades entre homens e mulheres deve ser orientada por dois princípios: a) desenvolvimento de serviços coletivos que permitam socializar parte dos custos dos cuidados com a família, evitando que tais custos recaiam exclusivamente sobre as mulheres; e b) implementação de mecanismos que visem tornar mais igualitária a divisão de tarefas no âmbito doméstico, para que os custos derivados da reprodução das famílias deixem de ser diretamente associados às mulheres.

O desenvolvimento insuficiente de políticas públicas que objetivam socializar os custos dos cuidados familiares, bem como o baixo nível de cobertura das políticas existentes e os altos índices de desrespeito à legislação em vigor revelam que o reconhecimento da problemática da conciliação entre trabalho e família no Brasil obtém, ainda, uma fraca legitimação social e política. Isso talvez aconteça porque, como argumentam Laís Abramo e Rosalba Todaro, os custos relacionados à reprodução social continuam sendo atribuídos às mulheres e considerados "bens gratuitos fornecidos pela natureza". '́ bom ressaltar, entretanto, que nossa sociedade não se reproduz apenas baseada na produção de bens e serviços transacionados no mercado. As atividades não mercantis, em especial a realizada no âmbito doméstico, são a base material para a manutenção da vida da coletividade humana, contribuindo social e economicamente para o funcionamento estável e contínuo da sociedade.

Sobre a implementação de mecanismos que visem tornar mais igualitária a divisão de tarefas no âmbito doméstico, argumenta-se, aqui, que tal medida é fundamental para que os custos derivados da reprodução das famílias deixem de ser diretamente colocados sobre as trabalhadoras e a elas associados. Nessa direção, todos os benefícios que a legislação trabalhista atualmente prevê para as mulheres, visando garantir seus direitos reprodutivos, devem ser revistos e estendidos, na medida do possível, aos trabalhadores homens com responsabilidades familiares. Um avanço importante nesse sentido seria a introdução de um sistema mais flexível de licença-parental, ${ }^{8}$ no qual o direito à licença

\footnotetext{
${ }^{7}$ ABRAMO e TODARO, 2008, p. 152.

${ }^{8}$ Chamamos aqui licença-parental aquela que é ofertada para ambos os pais e que pode ser usufruída de maneira compartilhada entre eles.
} 
com salário integral para cuidar do filho possa ser exercido indistintamente pelo pai ou pela mãe, tema que será discutido a seguir.

\section{Inércia do Estado e reprodução de estereótipos de gênero: o caso das licenças-maternidade e paternidade no Brasil}

O ano de 1943 marcou a introdução do tema da licença-maternidade no arcabouço jurídico brasileiro. A promulgação da Consolidação das Leis do Trabalho garantiu às mulheres empregadas o direito à licença remunerada (com salário integral) durante quatro semanas antes e oito semanas após o parto, sendo assegurado o retorno à função ocupada antes do afastamento para usufruto do benefício.

Foi, porém, com o advento da Constituição Federal (CF) de 1988 que a licençamaternidade passou a figurar como um direito social de todas as trabalhadoras urbanas e rurais que passaram a poder ausentar-se de seus empregos pelo prazo de 120 dias, sem prejuízo de salário ou de ocupação. Ao inserir a licença-maternidade no rol dos direitos sociais, o Estado brasileiro reafirmou e aprofundou seu compromisso com as recomendações da Organização Internacional do Trabalho (OIT), que, em sua Convenção 103, destaca a importância de que os Estados-membro adotem algum tipo de proteção à gestante. De fato, a maior parte dos países possui, hoje, em suas legislações trabalhistas algum dispositivo de proteção das mulheres durante o período de gravidez e após o parto. ${ }^{9}$

Os quatro meses de licença assegurados às mães brasileiras já colocavam o país entre aqueles com maiores períodos de licença-maternidade, seja em comparação com seus vizinhos latino-americanos, seja em relação aos países europeus. Em meados de 2008 , reforçando essa posição, foi promulgada a Lei $n^{\circ} 11.770$, que possibilita a ampliação desse período por mais dois meses, o que reacendeu um debate que já havia sido vivenciado durante todo o processo constituinte, quando o movimento feminista e de mulheres produziu reflexões que expressavam posições divergentes sobre as consequências de um benefício nos moldes da licença-maternidade pensada. Por um lado, muitas foram as manifestações que expressaram o entendimento de que a nova Lei, a exemplo da CF, representa o reconhecimento pelo Estado da maternidade como uma função social, devendo, portanto, ser percebida a partir da ótica de um direito justo e necessário. Outras defesas vieram também pela lógica da proteção à infância, uma vez que o Estado recomenda a amamentação exclusiva até os seis meses de vida dos bebês e a licença ampliada contribuiria para o alcance dessa meta.

Por outro lado, há avaliações de que a ampliação da licença representaria uma barreira extra a dificultar a participação (igualitária) da mulher no mercado de trabalho, uma vez que representaria um custo adicional ao trabalho feminino. Críticas mais intensas afirmaram que a nova legislação não representa nenhum avanço em direção à promoção de iguais responsabilidades familiares entre homens e mulheres, mas, ao contrário, reforça a maternidade como destino e habilidade feminina, eximindo o Estado de seu papel na formação e no cuidado com as crianças e não estimulando - ou mesmo ignorando - o comprometimento dos homens com a paternidade responsável. ${ }^{10}$

De fato, não há no país nenhuma discussão no campo legislativo para a implementação de uma licença-parental, no molde das experiências vivenciadas por um grande

\footnotetext{
9 Grazila ANSILIERO, 2007.

${ }^{10}$ Verônica FERREIRA, 2008.
} 
número de países, em especial os europeus. O único reconhecimento que o Estado brasileiro dá ao valor do exercício da paternidade presente e participativa é o direito à licençapaternidade de cinco dias, tal como definida na Constituição de 1988, benefício não estendido para os pais que tenham adotado uma criança, independentemente da idade que ela tenha. ${ }^{11}$

A despeito das inúmeras transformações observadas ao longo dos anos nas estruturas familiares brasileiras - tanto em termos de composição quanto de valores e atitudes reproduzidas -, a legislação nacional ainda mantém um viés extremamente sexista no que diz respeito ao entendimento de quais sejam as competências e responsabilidades de homens e mulheres no exercício da paternidade e da maternidade.

Se o Brasil é um dos países que garantem um dos períodos mais extensos de licençamaternidade, é também o que assegura um período mínimo de licença para que os pais exerçam exatamente o mesmo direito garantido às mulheres. Tal percepção não apenas desestimula a participação dos pais, como também reforça a ideia da maternidade como destino feminino, do cuidado como habilidade natural das mulheres e do trabalho feminino como mais custoso para empregadores.

É importante reforçar que a licença-maternidade se trata da garantia de um direito das mulheres: o direito ao exercício pleno da maternidade. Um direito que não diz respeito apenas à população feminina, mas a toda a sociedade. Ao dedicarem-se ao cuidado dos filhos em seus primeiros meses de vida, as mulheres estão não apenas exercendo esse direito, como também cumprindo com uma função social que beneficia toda a população. É, portanto, responsabilidade do Estado assegurar-lhes esse direito.

No entanto, esse argumento também é válido para os homens, tendo em vista que a licença para o cuidado dos filhos deve ser reconhecida como um dever não apenas da mulher que se torna mãe, mas também do homem que se torna pai. O cuidado das crianças está previsto na Constituição Federal, art. 227, como um dever e um direito do Estado, da sociedade e da família - das mães e dos pais -, ou seja, homens e mulheres têm o mesmo dever e a mesma capacidade de cuidar de seus filhos.

No caso específico das licenças-maternidade, paternidade e parental, alguns estudos têm demonstrado que, quando o Estado se reconhece como ator importante na construção de uma nova cultura - desenvolvendo estratégias de estímulo ao compartilhamento de responsabilidades familiares e considerando as diversidades das estruturas familiares vigentes -, tanto mães quanto pais, filhos e sociedade de modo geral se beneficiam. ${ }^{12}$ Além de outros ganhos, a existência de licenças-paternidade mais extensas ou de licenças-parental mais extensas contribui para a construção de novos modelos de masculinidade e feminilidade que, espera-se, valorizem a corresponsabilidade, o compartilhamento de tarefas e o exercício da paternidade responsável.

A previsão de licenças compartilhadas representa uma ação proativa do Estado na garantia da aplicação do mesmo dever e do mesmo direito de cuidado com os filhos a mães e pais. Tal perspectiva contribui para a reconstrução de valores e expectativas relacionadas ao papel de homens e mulheres na sociedade e no âmbito da família.

As experiências de licença-parental experimentadas pioneiramente pela Suécia e posteriormente pelos demais países nórdicos certamente em muito têm contribuído para a emancipação e a promoção da autonomia das mulheres, constituindo-se, assim, em paradigmas para a construção de novas formas de ação e intervenção política. A

\footnotetext{
${ }^{11}$ A Lei no 10.421/2002 estende apenas à mãe adotiva o direito à licença-maternidade e ao saláriomaternidade, alterando a Consolidação das Leis do Trabalho (CLT).

12 Gary BARKER, 2008.
} 
perspectiva que orientou, portanto, a construção e o desenvolvimento de iniciativas dessa natureza partiu do seguinte pressuposto:

\begin{abstract}
Esperava-se que as mulheres fossem economicamente independentes de seus parceiros e tão responsáveis quanto eles pelo suporte econômico dos filhos. Os homens deveriam ser igualmente responsáveis pelo trabalho doméstico e pelos cuidados com as crianças. A divisão de tarefas na família era vista como um pré-requisito para a plena participação das mulheres na economia, na política e nos sindicatos e como um modo de aumentar as oportunidades de auto-realização dos homens como pais e como pessoas que têm interesses outros além daqueles relacionados ao mercado de trabalho. ${ }^{13}$
\end{abstract}

Para o caso brasileiro - e também para as demais nações latino-americanas e caribenhas -, a implementação de iniciativas como a licença-parental ou no mínimo a ampliação significativa da licença-paternidade traria importantes resultados tanto do ponto de vista simbólico - da possibilidade de construção de uma nova cultura - quanto das possibilidades de participação das mulheres no mercado de trabalho.

Vale enfatizar que medidas dessa natureza não apenas contribuiriam para reduzir a associação direta que se faz entre os custos derivados do cuidado dos filhos às mulheres trabalhadoras, como também para aumentar a cobertura dessas licenças. Conforme já enfatizado, o direito à licença-maternidade no Brasil só é garantido às trabalhadoras formais, que são a minoria entre as ocupadas. Garantir o acesso desse benefício aos homens ocupados, que estão relativamente mais presentes em ocupações formais, significa, portanto, aumentar consideravelmente o número de famílias amparadas pela legislação.

A promulgação de uma nova legislação, contudo, não é capaz de, por si só, alterar o quadro de desigualdades e reprodução de preconceitos que marca a sociedade brasileira. De fato, os países que adotaram as licenças-parental enfrentam desafios relacionados à ainda baixa utilização do benefício pelos homens, mesmo tendo havido um crescimento importante ao longo das décadas. No caso da Suécia - que conta com o sistema mais flexível -, apenas $16 \%$ de todo o período da licença-parental era usufruído pelos pais em 2002 (em 1995, esse valor era de 10,3\%). O número de homens suecos que usufruiu da licença-parental neste ano alcançou $71 \%$ do número de mulheres na mesma condição. Contribuem para a conformação desse quadro não apenas fatores de ordem sociocultural, mas também as características do próprio sistema de licenças ${ }^{14}$ e a estrutura do mercado de trabalho de cada país.

Não se estão desprezando, aqui, as dificuldades que devem ser vencidas para que as licenças-parental se tornem uma realidade nos países, mas sua importância é inegável num contexto de promoção da igualdade entre homens e mulheres. É fundamental que a sociedade e os diversos setores do Estado discutam a ampliação do direito às licençasmaternidade e paternidade, bem como a instituição de sistemas de licença-parental, momento no qual discutiremos as possibilidades de mudanças mais profundas na ordem de gênero patriarcal que estrutura a sociedade e caminharemos em direção a uma realidade de maior justiça social e de maior igualdade de direitos.

\title{
Referências bibliográficas
}

ABRAMO, Laís; TODARO, Rosalba. "Custos do trabalho de homens e mulheres na América Latina". In: COSTA, Albertina et al. (Orgs.). Mercado de trabalho e gênero: comparações internacionais. Rio de Janeiro: FGV, 2008. p. 141-158.

\footnotetext{
${ }^{13}$ Carl HWANG, 1987 apud Carlos Aurélio Pimenta FARIA, 2002, p. 184.

${ }^{14}$ Frida Rós VALDIMARSDÓTTIR, 2006.
} 
ALVES, José Eustáquio; CAVENAGHI, Suzana. Novos arranjos familiares: o casal DINC no Brasil. 2007. Mimeogrado. Disponível em: www.ie.ufrj.br/aparte/pdfs/dinc_27ago07.pdf. Acesso em: 5 nov. 2009.

ANSILIERO, Graziela. "Histórico e evolução recente da concessão de salários-maternidade no Brasil". Informe da Previdência Social, Brasília, v. 19, n. 2, p. 1-9, fev. 2007.

BARKER, Gary. La participación del hombre como padre en la región de Latinoamérica y el Caribe: una revisión de literatura crítica con consideraciones para políticas. Brasil: Promundo; Save the Children, 2008.

FARIA, Carlos Aurélio Pimenta. "Entre marido e mulher, o Estado mete a colher: reconfigurando a divisão do trabalho doméstico na Suécia". Revista Brasileira de Ciências Sociais, São Paulo, v. 17, n. 48, p. 173-196, fev. 2002.

FERREIRA, Verônica. "Licença maternidade de 6 meses: solução ou retrocesso?" Articulando eletronicamente, Recife, n. 128, set. 2008.

PINHEIRO, Luana et al. Retrato das desigualdades de gênero e de raça. 3. ed. Brasília: Ipea, 2008.

VALDIMARSDÓTTIR, Frida Rós. Nordic Experiences with Parental Leaves and its Impacto on Equality between Women and Men. Denmark: Nordic Council of Ministers, 2006. New Family Arrangements, Old Gender Social Conventions: Parental Leave as
Public Policy to Deal with these Tensions

Abstract: The aim of this paper is to address the gap between the actual changes in the family structure and how the State deals with these matters through public policies which only take into account a strict and conventional model of family (nuclear families, consisting of couples with children), which reaffirms traditional gender conventions. As an example of this gap, we will present the case of work leave for the care of dependents, taking into account the information produced in the research Portrait of Inequalities, that highlights the establishment of new types of family structure.

Key Words: Gender; Women; Public Policies; Parental Leave; Maternity Leave. 